\title{
O CONTRIBUTO DA EXPERIÊNCIA GASTRONÓMICA PARA O ENRIQUECIMENTO DA EXPERIÊNCIA TURÍSTICA. PERSPETIVAS DE UM ESTUDO NO ALGARVE, PORTUGAL ${ }^{1}$
}

CONTRIBUTION OF THE GASTRANOMIC EXPERIENCE TO ENHANCING TOURISTS' EXPERIENCE. PERSPECTIVES OF A STUDY IN THE ALGARVE, PORTUGAL

LA CONTRIBUCIÓN DE LA EXPERIENCIA GASTRONÓMICA PARA EL ENRIQUECIMIENTO DE LA EXPERIENCIA TURISTIICA. PERSPECTIVAS DE UN ESTUDIO EN EL ALGARVE, PORTUGAL

Joana Teresa Santos

Universidade do Algarve Mestre em Marketing pela Faculdade de Economia da Universidade do Algarve Faro, Portugal joanateresa.geral@gmail.com

\section{Patrícia Susana Lopes Guerrilha dos Santos Pinto} Universidade do Algarve

Docente da Faculdade de Economia da Universidade do Algarve Doutora em Métodos Quantitativos aplicados à Economia e à Gestão na especialidade de Estatística pela Universidade do Algarve

Faro, Portugal pvalle@ualg.pt

1 Este trabalho é financiado por fundos nacionais provenientes pela FCT - Fundação para a Ciência e Tecnologia através do projeto UID/SOC/04020/2013. 
Manuela Guerreiro

Universidade do Algarve

Docente da Universidade do Algarve

Doutora em Ciências Económicas e Empresariais pela Faculdade de Economia da

Universidade do Algarve

Faro, Portugal

mmguerre@ualg.pt

Data de Submissão: 27/05/2016

Data de Aprovação: 18/07/2016

RESUMO: É geralmente aceite que o património cultural e histórico dos destinos turísticos é fonte importante para a criação de produtos turísticos diferenciados e atrativos. A gastronomia é um dos recursos culturais mais relevantes, atualmente reconhecida pela UNESCO como Património Imaterial da Humanidade. Além disso, este conjunto de recursos encerra uma reconhecida capacidade para estimular a vivência de experiências turísticas únicas e diferenciadoras. O objetivo deste artigo é caraterizar a experiência gastronómica vivida pelos turistas durante a sua estada num destino turístico maduro, bem como determinar qual o papel das experiências gastronómicas na formação da satisfação global e da fidelidade ao destino. O destino objeto de estudo é o Algarve, um dos principais destinos turísticos de Sol e Praia da Europa e o principal destino turístico português. Foram inquiridos 384 turistas no Aeroporto Internacional de Faro através da administração de um inquérito por questionário. A análise dos resultados, essencialmente do tipo quantitativo, assentou no uso do softwares Statistical Package for Social Sciences (SPSS). O software NVivo foi usado para analisar as questões de resposta aberta. O presente trabalho contribui para a análise da gastronomia como um produto turístico complementar num destino fundamentalmente associado ao sol e à praia. Em particular, demonstra-se que a gastronomia assume um papel de destaque na oferta de um destino e, cada vez mais, constitui uma experiência fonte de prazer e de enriquecimento cultural.

PALAVRAS-CHAVE: Turismo cultural, Experiência gastronómica, Satisfação.

ABSTRACT: It is generally accepted that the cultural and historical heritage of tourist destinations are important sources for designing differentiated and attractive tourism products. Gastronomy, one of the most important cultural resources, is now recognized by UNESCO as an Intangible Heritage of Humanity. In addition, gastronomy has a recognized ability to stimulate unique and distinctive tourist experiences. The aims of this paper are to characterize the gastronomic experiences of tourists during their stay in a mature tourist destination, and to determine the role of these experiences on overall satisfaction and loyalty to the destination. The research setting is the Algarve, one of the main "sun, sea and sand" tourism destinations in Europe and the top tourism destination in Portugal. A survey was conducted of 384 tourists who passed through Faro International Airport. The results, essentially quantitative, were obtained using the software program Statistical Package for Social Sciences (SPSS). The software program NVivo was used to analyze the open-ended questions. This work contributes to the study of gastronomy as a complementary tourism product in a destination primarily associated with the sun, sea and sand. In particular, it demonstrates that gastronomy plays a leading role in the destination offer, and increasingly, provides a source of pleasure and cultural enrichment. 
KEYWORDS: Cultural tourism, Gastronomic experience, Satisfaction.

RESUMEN: Generalmente se acepta que el patrimonio cultural e histórico de los destinos turísticos es una fuente importante para la creación de productos turísticos diferenciados y atractivos. La gastronomía es uno de los recursos culturales más relevantes, actualmente reconocida por la UNESCO como Patrimonio Inmaterial de la Humanidad. Además, este conjunto de recursos encierra una reconocida capacidad de estimular la vivencia de experiencias turísticas únicas y diferenciadoras. El objetivo de este artículo es caracterizar la experiencia gastronómica vivida por los turistas durante su estancia en un destino turístico maduro, así como determinar cuál es el papel de las experiencias gastronómicas en la formación de la satisfacción global y de la fidelidad al destino. El destino objeto de estudio es el Algarve, uno de los principales destinos turísticos de sol y playa de Europa y el principal destino turístico portugués. Fueron encuestados 384 turistas en el Aeropuerto Internacional de Faro a través de la aplicación de las preguntas de un cuestionario. El análisis de los resultados, esencialmente de tipo cuantitativo, se basó en el uso del Softwares Statistical Package for Social Sciences (SPSS). El software NVivo fue usado para analizar las cuestiones de respuesta abierta. El presente trabajo contribuye para el análisis de la gastronomía como un producto turístico complementario en un destino fundamentalmente asociado al sol y a la playa. En particular, se demuestra que la gastronomía asume un papel de destaque en la oferta de un destino y cada vez más constituye una experiencia fuente de placer y de enriquecimiento cultural.

PALABRAS CLAVE: Turismo cultural; Experiencia gastronómica; Satisfacción.

\section{INTRODUÇÃO}

gastronomia ocupa hoje em dia um lugar de destaque em nível
mundial sendo considerada Património Mundial da Humanidade
pela UNESCO. A atribuição desta classificação é enquadrada pela Convenção para a Salvaguarda do Património Cultural Imaterial (2003) e é atribuída "a todo aquele património que deve ser salvaguardado e o qual consiste no reconhecimento dos usos, representações, expressões, conhecimentos e técnicas transmitidos de geração em geração e que infundem nas comunidades e grupos um sentimento de identidade e continuidade contribuindo, assim, para promover o respeito pela diversidade cultural e pela criatividade humana" (UNESCO, 2003:3).

O termo gastronomia encontra-se vulgarmente associado a uma utilização sofisticada de alimentos e a um comportamento requintado do seu consumo. Etimologicamente a palavra deriva do grego antigo gastér, que significa estômago, e de nómos, que se refere a conhecimentos ou lei. A gastronomia pode ser associada ao "conhecimento das leis ou ao conhecimento relativo ao 
ISSN: 1983-7151

estômago" e é definida como a "a arte do bem comer e do bem saber escolher a melhor bebida para acompanhar a refeição" (Gimenes, 2012:187)

O estilo de vida predominante nas sociedades contemporâneas ocidentais propicia o aumento da visibilidade da gastronomia, pois o consumo de refeições (geralmente associado ao vinho) tornou-se parte significativa do estatuto social e, ela própria, uma extensão da cultura social dominante (Hall \& Mitchell, 2000). Neste contexto, a elevada qualidade dos ingredientes, a criatividade dos chefs e a apresentação estética dos menus são aspetos cada vez mais relevantes na decisão de consumo (Richards, 2015:2).

Oturista contemporâneo, quando parte em viagem, procura viver experiências autênticas e inovadoras e atribui um crescente valor aos recursos naturais e culturais específicos de cada região (Poon, 1998; Gale, 2005). Numa época em que a economia das experiências (Pine $\&$ Gilmore, 1999) ganha destaque, o turismo cultural é definido em função dos espaços visitados e dos objetos identificados como culturais usufruídos durante a estada, tais como museus, festivais, eventos e gastronomia (Köhler, 2013).

O Algarve é um dos principais destinos turísticos costeiros em Portugal e encontra-se atualmente entre os 20 mais importantes do mundo. O clima quente nos meses de verão e uma extensa costa com praias e infraestruturas turísticas adequadas atraem milhares de turistas à região sobretudo durante $\mathrm{O}$ verão. A sazonalidade do turismo é um dos problemas que a região enfrenta, agravada pela emergência de outros destinos turísticos de sol e praia na bacia do mediterrâneo que competem entre si para atrair segmentos semelhantes de turistas (britânicos, espanhóis, alemães, franceses e holandeses). Face a esta situação, as entidades responsáveis pela gestão do destino Algarve têm vindo a reconhecer a necessidade de diversificar a oferta turística da região (Cruz, 2010; Valle, Guerreiro, Mendes \& Silva, 2011). Deste modo, a identificação de produtos turísticos complementares aos produtos turísticos principais - sol e praia e golf - tem suscitado a aposta em recursos culturais únicos e diferenciados com capacidade para ir ao encontro das necessidades e dos desejos dos turistas. A gastronomia no Algarve, geralmente associada à Dieta Mediterrânica (reconhecida pela UNESCO como Património Imaterial da Humanidade desde 
2013), tem vindo a ganhar espaço como dos produtos turísticos emergentes e com peso relevante na satisfação e na fidelidade dos turistas que visitam a região (Valle et al., 2011; Guerreiro, Pinto \& Mendes, 2016).

O principal objetivo deste estudo é caraterizar a experiência gastronómica dos turistas no Algarve. Este objetivo geral encontra-se traduzido nos seguintes objetivos específicos: 1) caraterizar a experiência gastronómica na região, em particular, analisando a importância da experiência gastronómica no contexto da visita, identificando os motivos mais relevantes pelos quais o turista não experimentou a gastronomia local, bem como os atributos mais relevantes da experiência gastronómica, revelando os adjetivos que espontaneamente os turistas associam às suas experiências gastronómicas, satisfação e emoções que associam a essas experiências ; 2) analisar a fidelidade à experiência gastronómica e à região, com especial relevo para a influência desta na intenção de revisitar o destino. Para o efeito foram inquiridos 384 turistas na zona de partidas do Aeroporto Internacional de Faro, capital do Algarve, através de um inquérito por questionário autoadministrado, o que enquadra o trabalho numa pesquisa de natureza quantitativa. O trabalho contribui para o estudo da gastronomia como um produto turístico complementar ao tradicional 'sol e à praia' num destino turístico maduro. Esta pesquisa pode ter implicações importantes na gestão do destino ao permitir aos gestores públicos e privados ligados ao turismo, assim como à entidade responsável pela gestão do mesmo, conhecer e compreender com detalhe uma dimensão concreta da experiência turística - a experiência gastronómica - e assim direcionar futuras ações de marketing com base neste importante produto.

\section{CULTURA E TURISMO}

Os conceitos de cultura e de turismo cultural são cada vez mais latos, o que permite diversificar e enriquecer, quer na perspetiva da oferta quer na perspetiva da procura, a abrangência e a natureza da experiência turística. Um conjunto sustentado de alterações estruturais na sociedade contemporânea tem vindo a atribuir mais importância à cultura como produto de consumo (UNESCO, 2010). Numa época em que a economia das experiências (Pine \& 
ISSN: 1983-7151

Gilmore, 1999) ganha destaque, o turismo cultural é definido em função dos espaços visitados e dos objetos identificados como culturais usufruídos durante a estada, tais como museus, festivais, eventos e gastronomia (Köhler, 2013).

De acordo com o entendimento da UNESCO (2002), expresso através da Declaração da Cidade do México - Declaração Universal Sobre a Diversidade Cultural -, cultura é entendida como "o conjunto dos traços distintivos espirituais e materiais, intelectuais e afetivos que caracterizam uma sociedade ou um grupo social e que abrange, além das artes e das letras, os modos de vida, as maneiras de viver juntos, os sistemas de valores, as tradições e as crenças" (UNESCO, 2002: 2). Esta definição, por ser ampla, vai para além da arte e do património e abarca toda uma teia labiríntica de aspetos que, no seu todo, definem uma determinada sociedade em termos culturais (Mendes, Henriques \& Guerreiro, 2015). Na verdade, embora a cultura sempre tenha estado relacionada com o turismo, na atualidade deixou de se assumir como o principal objetivo do turismo, na medida em que, como sublinha Urry (1990), turismo é cultura. Do mesmo modo, para MacCannell (1993 in Richards, 1996: 25), "todo o tipo de turismo envolve uma experiência cultural".

Ao incluir a cultura nas estratégias da atividade turística, cuja cultura é um elemento chave no desenvolvimento do turismo, verifica-se um aumento da atratividade das regiões. A cultura é tida como um elemento de identidade regional, podendo afirmar-se como um fator de competitividade de base territorial (OMC, 2012; Mendes et al., 2015).

No seio da comunidade académica, a definição de Turismo Cultural não é consensual (Hughes, 1987; Dolnicar, 2002; Stylianou-Lambert, 2011), como também não o é no seio da indústria turística. O Turismo Cultural é um conceito recente, embora, na Europa, turismo e cultura sempre tenham estado intimamente ligados (Richards, 1996). Vários autores (Crompton \& McKay, 1997; Valle et al., 2011) reconhecem que determinados segmentos de turistas procuram, nas suas férias, viver experiências turísticas que contribuam para o seu enriquecimento pessoal e, simultaneamente, satisfazer necessidades culturais (Richards, 1996). Deste modo, ainda que essencialmente motivados por outro tipo de atrações turísticas (por exemplo, a praia), os turistas apreciam o contacto com produtos de base cultural, na medida em que as 
mesmas contribuem para aprender e assim alargar a sua cultura geral (Valle et al., 2011).

A oferta cultural pode ter um impacto crescente na satisfação dos turistas, particularmente em destinos costeiros (Valle et al., 2011), sendo que vários estudos comprovam a preferência pelos lugares turísticos que contemplam uma oferta cultural complementar ao "sol e ao mar" tradicional (Hewison, 1987; Hughes, 1987; Richards, 2002; Chapman \& Speake, 2011; Valle et al., 2011). Verifica-se, quer entre a academia quer entre os profissionais responsáveis pela gestão dos destinos turísticos, um crescente reconhecimento da importância e da pertinência na exploração das características únicas dos destinos, nomeadamente no que diz respeito ao seu património cultural e histórico, como fonte de desenvolvimento de produtos com capacidade para estimular a vivência de experiências turísticas únicas e diferenciadoras (Smith, 2004; Agarwal \& Brunt, 2006; Costa, 2009; Valle et al., 2011; Henriques, Mendes, Guerreiro, Afonso \& Mendes, 2014).

\section{EXPERIÊNCIA TURÍSTICA E EXPERIÊNCIA GASTRONÓMICA}

A atitude mais proactiva dos turistas na procura de experiências autênticas e diferenciadas tem conduzido a que os destinos, na prossecução do seu desenvolvimento, procurem proporcionar uma experiência de aprendizagem e de transformação do "eu" (Richards \& Wilson, 2006; Guerreiro, Mendes \& Henriques, 2014; Mendes et al., 2015).

A necessidade de diferenciação, por parte da oferta, e a busca por experiências exóticas e inovadoras, por parte da procura, convergem para o desenvolvimento do conceito de experiência turística. Trata-se de um conceito lançado por Pine e Gilmore no final do século XX (1999) e parte do pressuposto de que "mesmo a mais banal das transações pode ser transformada numa experiência memorável" (Pine \& Gilmore, 1999: 4). Pine e Gilmore (1999:12) definem a experiência como o "conjunto de atividades nas quais os indivíduos se envolvem em termos pessoais". Oh, Fiore e Young (2007: 120) acrescentam que, "na perspetiva do consumidor", a experiência turística é algo "agradável, 
envolvente e memorável". Cada experiência é vivida de modo subjetivo por cada indivíduo que se envolve a nível físico, emocional, espiritual e intelectual (Tung \& Ritchie, 2011). A subjetividade da experiência turística é acentuada pela noção de que o valor esperado de uma experiência difere de indivíduo para indivíduo e em função de cada contexto situacional. Neste cenário, consumidores buscam experiências pessoais (Tung \& Ritchie, 2011).

Richards (2011), baseado no discurso da Economia da Experiência de Pine e Gilmore (1999), retira conclusões para o turismo. O autor argumenta que o turismo está a beneficiar desta perspetiva com o desenvolvimento de atrações temáticas, itinerários culturais e eventos encenados e destaca a evolução de uma perspetiva centrada na ótica da produção (turismo de massa) e do consumo (experiências) para a de integração de ambas as perspetivas (cocriação). O consumo cultural é uma forma de vivenciar experiências turísticas diferentes da rotina diária dos indivíduos (Köhler, 2013). Esta ideia explica, em grande parte, o investimento em ofertas turísticas realizado pelos diversos destinos (países, regiões e cidades) com o intuito de divulgar a cultura local, atrair turistas e gerar receitas (Köhler, 2013).

Com a importância crescente do "simbólico" (Lash \& Urry, 1994; Zukin, 2004) e das "experiências" (Pine II \& Gilmore, 1999), num cenário globalizado em que ganham importância aspetos relacionados com a identidade local, a cultura tornou-se um dos principais bens de consumo com impacto nos níveis de procura turística (Richards, 1996). É a combinação de fatores inerentes ao contexto e à satisfação relativamente a cada um dos serviços comprados e consumidos ao longo do desenvolvimento de uma experiência, por natureza holística, que determina o nível global de satisfação dos turistas (Guerreiro et al., 2014; Mendes et al., 2015).

Henriques e Custódio (2010:77) enfatizam que um dos mais importantes atrativos turístico-culturais de um local, região ou país é a gastronomia, realçando ainda que "a gastronomia é reconhecida enquanto património valorizador da identidade cultural do destino e da experiência turística". A realização de refeições em contexto turístico adquire um sentido especial e representa uma forma de prazer e de fuga à rotina, afirmando-se como um elemento cada vez 
mais central da experiência turística e, em alguns casos, chega a ser como a principal razão para visitar diversos destinos (Richards, 2015).

O consumo de refeições envolve práticas sociais que ultrapassam o mero propósito da supressão de necessidades fisiológicas de subsistência, passando a ser uma forma de relacionamento social, cultural e político (Chang, Kivela \& Mak, 2010; Mak, Lumbers \& Eves, 2012). A gastronomia encontra-se frequentemente associada "a uma culinária mais requintada, capaz de propiciar um prazer superior ao obtido pelo mero ato de se alimentar" pelo que, independentemente do "grau de complexidade ou especificidade da forma de preparo e das técnicas utilizadas, a experiência gastronómica é associada a uma experiência prazerosa" (Gimenes, 2012: 189).

Apesar de a gastronomia envolver estímulos direcionados para todos os sentidos, deve realçar-se o papel do paladar pois este serve "de proteção contra elementos potencialmente prejudiciais ao organismo" (Gimenes, 2012: 189). De acordo com Kivela e Crotts (2006), comer é a única forma de fazer um turismo que gratifica todos os cinco sentidos - visão, tato, audição, paladar e olfato. Deste modo, se oferece aos turistas uma sensação de prazer que pode preencher a parte experiencial da experiência turística (Hjalager \& Richards, 2002, in Mak et al., 2012: 171-172). A experiência gastronómica é indissociável da "experiência emocional, que tem início no processo químico do paladar"(Gimenes, 2012:192). De acordo com Bosque e Martín (2008), as emoções evocadas durante uma experiência de consumo deixam traços afetivos na memória que irão impactar diretamente a formação da satisfação global (Lee, Scott \& Packer, 2014). Quer isto dizer que as emoções e o ambiente cultural envolvente desempenham um papel fundamental na perceção da experiência gastronómica.

Um recurso turístico compreende os recursos potencialmente atrativos para fins turísticos (Mendes, Henriques \& Guerreiro, 2015). Diversas entidades oficiais e autores enquadram a gastronomia no conjunto dos recursos culturais (UNESCO, 2009; Csapó, 2012; Köhler, 2013; Mendes, Henriques \& Guerreiro, 2015) com potencial para desenvolvimento turístico. Neste sentido, um recurso cultural, uma vez reconhecido pelo mercado, é potencialmente um produto turístico e resulta de um conjunto de recursos selecionados através de processos 
de interpretação (Guerreiro et al., 2014). Aqui reside a pertinência de se conhecer com detalhe o contributo da experiência gastronómica para o enriquecimento da experiência turística nos destinos turísticos.

De realçar que "a gastronomia se tornou um atributo importante na promoção turística" dos lugares (Richards, 2002: 5) devido à sua relação com a respetiva identidade a qual se traduz numa "forte correlação entre determinadas regiões e certos tipos de comida", propiciando uma "ligação íntima entre a paisagem e a gastronomia" (Richards, 2015: 2). Mark et al. (2012: 172) reforçam esta ideia ao aludirem a diversos estudos segundo os quais "os interesses e preferências dos turistas pela gastronomia de um destino podem desempenhar um papel significativo na escolha do destino". Do mesmo modo, Hall \& Mitchell (2005) consideram que, cada vez mais, a gastronomia e os vinhos são um fator relevante na decisão de viajar. De acordo com Valle et al. (2011), a satisfação do turista com os consumos culturais no local de férias (entre os quais as suas experiências gastronómicas) contribuem simultaneamente para o enriquecimento pessoal do indivíduo e para o reforço de sentimentos de lealdade ou fidelidade ao destino.

\section{FIDELIDADE, SATISFAÇÃO E GASTRONOMIA}

A fidelidade é um constructo que pode ser conceptualizado em diversas perspetivas (Oliver, 1999), sendo, na perspetiva de marketing, medido pela repetição das compras ou pela recomendação a outros consumidores (Pine et al., 1995). A fidelidade mede "a experiência de revisitação e o modo como o destino foi efetivamente recomendado em resultado da primeira visita" (Valle et al., 2006: 40). Os destinos turísticos também podem ser percebidos como um produto que pode ser revendido (revisitado) e recomendado a potenciais turistas como a família e amigos (Cai, Wu \& Bai, 2003; Valle et al., 2011).

Um turista satisfeito pode não voltar ao destino, mas irá certamente transmitir elementos positivos em relação ao mesmo, gerando em potenciais turistas vontade de descobrir o lugar. Apesar de ser expetável que o turista recomende o destino após uma experiência turística positiva e prazerosa, revisitar o mesmo implica custos de oportunidade. Além disso, 'apesar da familiaridade 
com o destino turístico, a satisfação global da experiência turística num destino específico é também considerada um indicador da intenção de preferência do turista pelo mesmo destino" (Valle et al., 2006: 26).

Estudos realizados no Algarve (Henriques \& Custódio, 2010; Valle et al., 2011; Guerreiro et al., 2016) permitiram concluir que, apesar de sobretudo motivados pelo sol e mar, uma proporção considerável dos turistas que visitaram a região procuravam ter outras experiências para além da praia. De acordo com os inquiridos, as paisagens naturais e rurais, a gastronomia e a visita a cidades e monumentos estão entre as principais atrações turísticas da região. Richards (2015) realça o notório crescimento do turismo gastronómico, no qual o interesse em gastronomia é parte da experiência de lazer.

\section{PROCEDIMENTOS METODOLÓGICOS}

Esta pesquisa desenvolveu-se no Algarve, uma região portuguesa localizada no extremo ocidental da Europa, a Sul de Portugal, com $4996,8 \mathrm{Km}^{2}$ de área e uma população residente de cerca de 444.390 habitantes distribuídos por 16 concelhos (Visitalgarve, 2014). O turismo é responsável por cerca de $60 \%$ do total de emprego e $66 \%$ do PIB regional. De salientar que o Algarve recebe anualmente cerca de 5 milhões de turistas (Visitalgarve, 2014).

A gastronomia, encarada como uma forma de expressão cultural, tem vindo a afirmar-se na região como um elemento marcante da identidade cultural dos povos, considerado património cultural intangível (Silva, 2013) e, potencialmente, um importante atrativo turístico-cultural dos lugares, sendo que, de acordo com Henriques e Custódio (2010: 69), "Portugal está identificado como um dos melhores destinos de gastronomia e vinhos da Europa". No âmbito dos produtos estratégicos para o desenvolvimento do turismo em Portugal, a gastronomia e vinhos tem vindo a conquistar grande relevância e potencial enquanto produto turístico (Turismo de Portugal, 2006). A região caracterizase pela aposta no tradicional sol e mar e, mais recentemente, no golfe como produtos estratégicos. Contudo, as entidades responsáveis pela gestão do destino têm, na última década, apostado no desenvolvimento de novos produtos que contribuam para atenuar a sazonalidade e complementar a oferta turística 
da região (Turismo de Portugal, 2013). Neste contexto, o produto gastronomia e vinhos surge como complemento da experiência turística na perspetiva da oferta (Turismo de Portugal, 2011), sendo necessário "diversificar atividades, desenvolver conteúdos e experiências, nomeadamente com a integração de produtos locais na operação das unidades turísticas, e integrar a oferta em plataformas de promoção e comercialização" (Turismo de Portugal, 2013:37). Além disso, é de incentivar a "criação de rotas gastronómicas e de vinhos", a realização de feiras e festivais gastronómicos, o envolvimento de restaurantes da região em atividades de promoção da gastronomia local, entre outros (Henriques e Custódio, 2010). Esta é uma perspetiva bem recebida pelos turistas que visitam o algarve (Valle et al., 2011; Guerreiro et al., 2016).

Tratando-se de uma pesquisa quantitativa, optou-se pelo desenho e implementação de um inquérito por questionário, constituído por cinco secções, cada uma das quais dando resposta a um objetivo específico da pesquisa: secção I: caracterizar a experiência gastronómica; secção II: caracterizar a imagem global do Algarve; secção III: caracterizar a satisfação global com a experiência gastronómica; secção IV: analisar a fidelidade em relação à experiência gastronómica no Algarve; secção V: caraterizar sociodemograficamente o respondente. Este estudo incide sobre os resultados apurados nas secções I, III, IV e V do instrumento de recolha de dados. Este questionário foi inicialmente elaborado em língua portuguesa e posteriormente traduzido para quatro idiomas: inglês, francês, castelhano ealemão. Após a realização de um pré-teste junto de 10 turistas em visita ao Algarve, foram introduzidos alguns ajustamentos decorrentes da análise das sugestões obtidas durante a sua administração. O Quadro 1 explicita a articulação entre os objetivos da investigação, a sua justificação com base na literatura e as perguntas do questionário.

O universo em estudo consistiu no conjunto de turistas estrangeiros que permaneceram pelo menos duas noites na região do Algarve e que consumiram gastronomia portuguesa durante a sua estada. Os inquéritos foram aplicados no período de outubro e novembro de 2014, época com reduzido fluxo turístico na região, permitindo caracterizar um tipo de turista de época baixa. Considerouse indispensável o número mínimo de duas noites, já que se pretendia garantir que o turista tivesse desfrutado de tempo necessário para consumir refeições 
no local de destino. Além disso, apenas foram considerados turistas estrangeiros que tivessem recorrido ao transporte aéreo, por ser este o tipo de turista que regista mais entradas na região. Os turistas portugueses não foram considerados no estudo pela sua familiaridade com a gastronomia portuguesa.

Quadro 1 Articulação entre os objetivos da pesquisa, questionário e fontes bibliográficas

\begin{tabular}{|c|c|c|}
\hline Objetivos da investigação & Estudos de referência & Perguntas do questionário \\
\hline $\begin{array}{l}\text { Caraterizar a experiência } \\
\text { gastronómica na região }\end{array}$ & $\begin{array}{c}\text { Bosque \& Martín (2008) } \\
\text { Gimenes (2012) } \\
\text { Henriques \& Custódio (2010) } \\
\text { Jun et al., (2001) } \\
\text { Lee, Scott \& Packer (2014) } \\
\text { Oh, Fiore \& Young (2007) } \\
\text { Richards (2015) } \\
\text { Richins (1997) } \\
\text { Tung \& Ritchie (2011) }\end{array}$ & $\begin{array}{l}\text { 1. Quando viaja, qual a importância de } \\
\text { experimentar a gastronomia típica desse país? } \\
\text { (escala de importância, tipo Likert, } 5 \text { níveis: 1- } \\
\text { nada importante 5- muito importante). } \\
\text { 2. Quando viaja, qual a importância de } \\
\text { realizar refeições fora (do hotel)? (escala de } \\
\text { importância, tipo Likert, } 5 \text { níveis: 1- nada } \\
\text { importante 5- muito importante). } \\
\text { 3. Experimentou gastronomia da região } \\
\text { durante a sua estadia no Algarve? } \\
\text { 4. Em que medida concorda com as seguintes } \\
\text { afirmações sobre a gastronomia Algarvia? } \\
\text { (escala de concordância, tipo Likert, } 5 \\
\text { níveis: } 1 \text { - discordo totalmente 5- concordo } \\
\text { totalmente). } \\
\text { Caso não conheça a gastronomia do Algarve, } \\
\text { indique o principal motivo (questão de } \\
\text { resposta livre). } \\
\text { 6. Em geral, como classifica a sua experiência } \\
\text { gastronómica no Algarve (escala tipo Likert, } 5 \\
\text { níveis: 1- dececionante 5- foi uma surpresa } \\
\text { magnífica). } \\
\text { 7. Use } 3 \text { adjetivos para descrever a experiência } \\
\text { gastronómica no Algarve. } \\
\text { 8. Como classifica a relação qualidade/preço } \\
\text { da comida portuguesa que experimentou } \\
\text { (escala de bondade, tipo Likert, } 5 \text { níveis: 1- } \\
\text { péssima 5- muito boa). } \\
\text { 9. Classifique as emoções que associa à } \\
\text { sua experiência gastronómica no Algarve } \\
\text { (4 escalas bipolares: satisfeito/insatisfeito; } \\
\text { encantado/descontente; impressionado/ } \\
\text { desapontado; surpreendido/chateado). }\end{array}$ \\
\hline $\begin{array}{l}\text { Caraterizar a fidelidade à } \\
\text { experiência gastronómica e } \\
\text { à região }\end{array}$ & $\begin{array}{c}\text { Cai, Wu \& Bai (2003) } \\
\text { Guerreiro et al. (2016) } \\
\text { Henriques \& Custódio } \\
\text { (2010) } \\
\text { Mark et al. (2012) } \\
\text { Valle et al. (2011) }\end{array}$ & $\begin{array}{l}\text { 10. Tem intenção de recomendar a comida } \\
\text { Algarvia aos seus amigos e familiares? } \\
\text { 11. Tem intenção de voltar a consumir comida } \\
\text { Algarvia? } \\
\text { 12. A experiência gastronómica vivida } \\
\text { no Algarve tem influência na intenção de } \\
\text { recomendar este destino turístico? } \\
\text { 13. Tem intenção de voltar ao destino turístico } \\
\text { Algarve devido à experiência gastronómica? }\end{array}$ \\
\hline
\end{tabular}

Fonte: Elaboração dos autores. 
Relativamente ao cálculo da dimensão da amostra para a presente investigação, recorreu-se à estimativa mais conservadora para uma proporção amostral ( $p=0,5)$, um nível de confiança de $95 \%$ e um erro máximo da amostra de $5 \%$. Concluiu-se, deste modo, que a dimensão da amostra deveria ser de 384 turistas. Todos os turistas estrangeiros presentes nas instalações do Aeroporto Internacional de Faro nos dias da semana e nos horários em que se aplicaram os questionários tiveram oportunidade de participar no estudo. Previamente à aplicação do questionário foi necessária a autorização da entidade que efetua a gestão aeroportuária para a realização da recolha de dados nas suas instalações. O entrevistador que aplicou o questionário possuía as necessárias aptidões linguísticas para apresentar o estudo e os seus objetivos, assim como proceder ao esclarecimento de eventuais dúvidas que surgissem no decorrer do preenchimento do formulário. Os dados obtidos por via do questionário, autoadministrado, foram analisados em função dos objetivos propostos para o trabalho, com recurso ao programa SPSS, versão 22, no que respeita às questões fechadas, e com o programa NVIVO 10, no que concerne à análise das questões de resposta aberta.

\section{ANÁLISE E DISCUSSÃO DOS RESULTADOS}

\section{CARACTERIZAÇÃO SOCIODEMOGRÁFICA DA AMOSTRA}

A amostra em estudo é constituída por $52,5 \%$ de turistas do género masculino e $47,5 \%$ do género feminino. A média das idades é de 44,8 anos ( $m o d a=57$ anos; mediana $=47$ anos). $A$ percentagem mais elevada de turistas, 25\%, encontra-se na faixa etária dos 50 a 59 anos, seguindose as faixas etária dos 40 aos 49 anos e dos 30 aos 39 anos, com 18\% de respostas cada. Verificou-se que a maioria dos turistas tem mais de 40 anos (62\% dos respondentes).

A maior parte dos turistas que participaram no estudo era casada ou vivia em união de facto (74\%), seguindo-se a categoria de solteiro 
(22,5\%). Quanto ao nível de escolaridade dos inquiridos, verificou-se que $65 \%$ da amostra era portadora de formação ao nível do 'Ensino Superior' (universitário), seguido de 32\% com 'Ensino Secundário' e apenas $4 \%$ da amostra referiu ter o 'Ensino Básico'. Relativamente à nacionalidade, a maioria dos turistas era proveniente do Reino Unido (53,9\%). A amostra englobava ainda $13,5 \%$ de turistas com origem na Holanda, $11 \%$ na Alemanha e 9\% em França.

A análise dos dados evidencia que o Algarve é sobretudo um destino turístico familiar, pois $66 \%$ dos turistas que visitaram este destino estavam de férias acompanhados pela 'Família'. Cerca de 25\% dos inquiridos revelaram ter vindo acompanhados por 'Amigos' e 4\% estavam acompanhados por outras pessoas nomeadamente namorado/a e 5\% estavam sozinhos. Em 60\% dos casos esta não era a primeira vez que os respondentes se encontravam de visita ao Algarve.

\section{CARACTERIZAÇÃO DA EXPERIÊNCIA GASTRONÓMICA}

Tendo como propósito conhecer detalhadamente a experiência gastronómica na região, o instrumento de recolha de dados incluiu questões que emergiram da revisão bibliográfica (Henriques e Custódio, 2010; Richards, 2015; Oh, Fiore e Young, 2007; Tung e Ritchie, 2011; Gimenes, 2012; Lee, Scott e Packer, 2014). O quadro 2 mostra que a maioria dos turistas inquiridos (85\% das respostas) considera importante ou muito importante experimentar a gastronomia típica do país que visita. Apenas $4 \%$ dos turistas revela pouco ou nenhum interesse em experimentar a gastronomia típica do país visitado. Além disso, 92\% dos inquiridos consideram importante ou muito importante realizar refeições fora do estabelecimento hoteleiro onde se encontra alojado. Este aspeto é bastante relevante, já que permite a interação com a comunidade local, bem como o contacto com a gastronomia típica da região.

Quadro 2 - Importância da experiência gastronómica no contexto da visita 


\begin{tabular}{|c|c|c|c|c|}
\hline $\begin{array}{c}1 \\
\text { Nada } \\
\text { importante }\end{array}$ & $\begin{array}{c}2 \\
\text { Pouco } \\
\text { importante }\end{array}$ & $\begin{array}{c}3 \\
\text { Indiferente }\end{array}$ & $\begin{array}{c}4 \\
\text { Bastante } \\
\text { importante }\end{array}$ & $\begin{array}{c}5 \\
\text { Totalmente } \\
\text { importante }\end{array}$ \\
\hline
\end{tabular}

Importância atribuída pelos

turistas a experimentar a gastronomia típica do país para onde viaja
Importância atribuída pelos turistas a realizar refeições fora (do hotel)

Fonte: Elaboração própria a partir dos outputs do SPSS

Cerca de $81 \%$ dos turistas respondentes afirmam ter experimentado a gastronomia da região durante a estada. Com o propósito de compreender as razões pelas quais os turistas não experimentaram a gastronomia local durante as suas férias, foi incluída no questionário uma questão de resposta livre. A principal razão apresentada (neste caso, por $52 \%$ dos turistas inquiridos) é o desconhecimento face à designação dos pratos, ao método de confeção dos mesmos e aos ingredientes tradicionais utilizados. Em termos de implicações para a gestão, nomeadamente no setor da restauração, sugere-se, por exemplo, a inclusão de imagens ilustrativas dos pratos, dos ingredientes e dos métodos de confeção nos menus. Além disso, os colaboradores em front office deverão ter formação específica no sentido de estarem aptos para responder a questões relacionadas com a gastronomia local.

Verifica-se ainda que $23 \%$ dos turistas não experimentaram a gastronomia local devido a desinteresse e que $16 \%$ prefere comida conhecida, rápida e barata, não demonstrando vontade de descobrir e experimentar a gastronomia local. Neste sentido deveriam ser realizados esforços de comunicação para despertar a curiosidade nos turistas em experimentar a gastronomia típica, com o desenho de mensagens destinadas a dar resposta a este tipo de obstáculos. Finalmente, existem 9\% dos turistas que não experimentaram a gastronomia da região por desconfiança face a sugestões, situação que pode ser colmatada pela referência aos ingredientes que compõem os pratos típicos, bem como pela inclusão de imagens ilustrativas e apelativas. A Figura 1 permite visualizar estas informações.

Figura 1 Motivos pelos quais o turista não experimentou a gastronomia do Algarve 


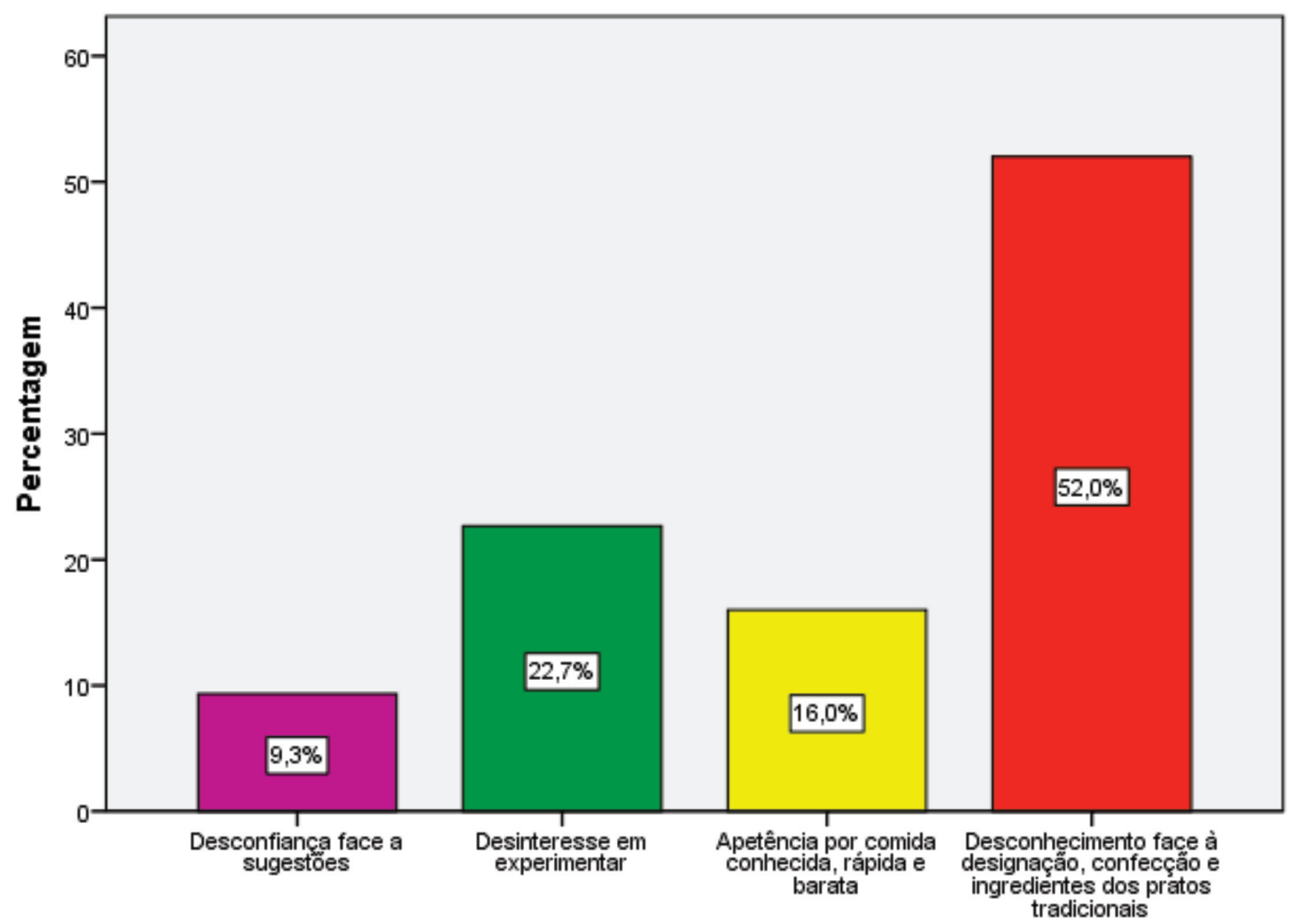

Fonte: Elaboração própria a partir dos outputs do SPSS

O Quadro 3 detalha algumas questões em relação à gastronomia algarvia, permitindo averiguar o grau de concordância com alguns aspetos relativos à experiência gastronómica na região do Algarve por parte dos turistas que afirmaram ter experimentado a mesma (de acordo com a escala proposta). A experiência gastronómica na região foi ainda estudada através da escala de Henriques e Custódio (2010), através de uma escala de concordância, de 5 níveis, em que 1- Discordo totalmente; 2- Discordo; 3- Não concordo nem discordo; 4- Concordo; 5- Concordo totalmente.

A maioria dos turistas respondentes afirmou concordar ou concordar totalmente (cerca de 90\%) que a gastronomia algarvia deve utilizar produtos locais, que a mesma desperta o interesse em saber o que se come no país e que estimula a curiosidade relativamente à cultura e à gastronomia típicas do país. Verifica-se também que a maioria dos turistas concorda ou concorda totalmente que a gastronomia algarvia permite conhecer novos pratos, proporcionando uma experiência de gastronómica com a qual os turistas não 
ISSN: 1983-7151

têm contacto habitualmente no seu país de origem (86,6\%). Além disso, permite experimentar novos sabores (86,1\%), contribui para uma maior diversidade da oferta gastronómica $(85,2 \%)$ ampliando o leque de opções disponíveis nas ementas dos restaurantes.

Quadro 3 Grau de concordância com afirmações sobre a experiência gastronómica no Algarve

\begin{tabular}{|cc|}
\hline A gastronomia algarvia ... & Concordam ou concordam Totalmente \\
\hline $\begin{array}{c}\text { Deveria utilizar produtos locais } \\
\text { Desperta o interesse em saber o que se come no país } \\
\text { Permite conhecer novos pratos } \\
\text { Permite experimentar novos sabores }\end{array}$ & $90,0 \%$ \\
\hline $\begin{array}{c}\text { Contribui para uma maior variedade da oferta gastronómica } \\
\text { região aos turistas }\end{array}$ & $89,6 \%$ \\
\hline $\begin{array}{c}\text { Constitui um veículo de marketing/promocão/divulgação da } \\
\text { valores da região }\end{array}$ & $86,6 \%$ \\
Propicia o conhecimento da identidade, tradições, costumes, & $86,1 \%$ \\
\hline $\begin{array}{c}\text { Estimula o conhecimento de produtos regionais } \\
\text { Desperta curiosidade em saber como são confecionados os } \\
\text { pratos e quais os seus ingredientes }\end{array}$ & $85,2 \%$ \\
\hline $\begin{array}{c}\text { Possibilita o desenvolvimento do turismo, da economia e } \\
\text { da região }\end{array}$ & $82,8 \%$ \\
\hline Encontra-se nos guias gastronómicos & $81,9 \%$ \\
\hline É sugerida pelos empregados de mesa ou aconselhada & $79,6 \%$ \\
\hline
\end{tabular}

Fonte: Elaboração própria a partir dos outputs do SPSS

Existe uma parte importante da amostra que concorda ou concorda totalmente que a gastronomia algarvia constitui um veículo de marketing/promoção da região como destino turístico $(82,8 \%)$, visto que promove os ingredientes típicos da região, permitindo um maior conhecimento e divulgação da mesma e potenciando um melhor conhecimento da cultura local. Além disso, propicia o conhecimento da identidade, tradições, costumes e valores do Algarve (81,9\%) e estimula o conhecimento de produtos regionais, permitindo um maior contacto com elementos característicos da região (81,2\%). Ainda, 79,6\% dos turistas concorda ou concorda totalmente que sentem curiosidade em saber como são confecionados os pratos e quais os seus ingredientes; $77,7 \%$ concorda ou concorda totalmente que a gastronomia da região possibilita o desenvolvimento do turismo, da economia e da região, estimulando a economia local através do consumo de produtos típicos da região. Estes resultados estão 
em linha com outros estudos entretanto publicados (Henriques \& Custódio, 2010; Richards, 2015).

Verifica-se, contudo, existir algum desconhecimento em relação à presença de aspetos relacionados com a gastronomia algarvia nos guias gastronómicos (54,7\% dos inquiridos confirmam esta tendência). Neste sentido é pertinente um incremento das publicações gastronómicas direcionadas a turistas em visita na região. Cerca de metade dos turistas respondentes $(50,5 \%)$ concorda ou concorda totalmente com a relevância da recomendação de ingredientes ou de pratos típicos partir de sugestões dadas por profissionais do setor da restauração (nomeadamente empregados de mesa) ou mesmo por taxistas. É assim pertinente sensibilizar estes grupos profissionais, reconhecidos como líderes de opinião locais, para o papel que podem desempenhar na divulgação da gastronomia típica da região.

Pretendeu-se ainda conhecer melhor a satisfação com a experiência gastronómica. Neste sentido, verifica-se que $43 \%$ dos turistas consideraram que 'a experiência gastronómica excedeu as expetativas' e que $11 \%$ referiram que 'foi uma surpresa magnífica'. Embora 42\% dos turistas considerem que a experiência gastronómica 'apenas correspondeu às expetativas', não se verificou registo de experiências gastronómicas com a classificação de 'dececionante'. Outros estudos desenvolvidos na região, e entretanto publicados, já haviam detetado o papel do consumo de gastronomia local durante a estada (Guerreiro, Pinto \& Mendes, 2016; Valle et al., 2011; Henriques \& Custódio, 2010). Nesta pesquisa, torna-se evidente que as experiências gastronómicas são avaliadas pelos turistas como fortemente satisfatórias, o que contribui para transformar a experiência turística global em algo único e memorável (em linha com a tese defendida por O, Fiore \& Young, 2007). Além disso, cerca de 89\% dos turistas inquiridos que experimentaram a gastronomia local consideram a relação qualidade/preço boa ou muito boa.

No sentido de melhor compreender a experiência gastronómica, foi incluída no questionário uma questão de resposta livre na qual era pedido aos respondentes para descreverem as suas experiências através de adjetivos. A nuvem de palavras que consta da Figura 2 permite visualizar os adjetivos 
espontaneamente referidos pelos turistas respondentes. A gastronomia local é sobretudo descrita como 'saborosa' (14,2\% das respostas), 'fresca' e 'deliciosa' ( $8,8 \%$ e $8,4 \%$ das respostas, respetivamente). Além disso, a nuvem de palavras permite ainda visualizar adjetivos 'boa' (7,4\% das respostas), 'excelente', 'acessível', 'agradável', 'atendimento', 'diversificada' (com cerca de 5\% de menções cada).

Figura 2 Adjetivos que descrevem a experiência gastronómica no Algarve

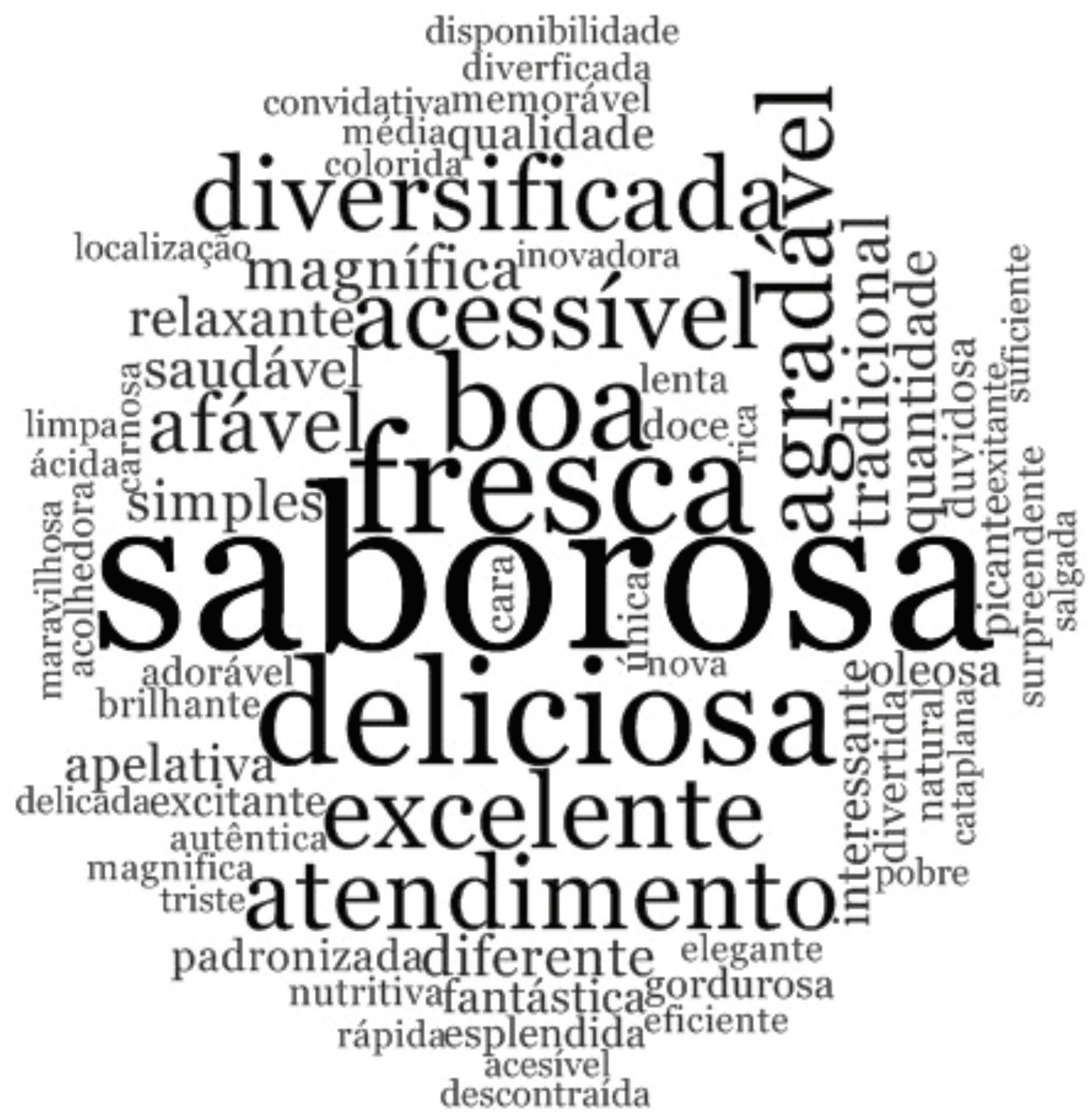

Fonte: Output do Nvivo.

O reconhecimento de que existe uma forte relação entre os sentimentos e as emoções vividas durante a experiência e a satisfação com a própria experiência turística (Oh, Fiore \& Young, 2007; Bosque \& Martín, 2008; Tung \& Ritchie, 2011; Gimenes, 2011; Lee, Scott \& Packer, 2014) justifica a inclusão de uma 
escala bipolar, tipo diferencial semântico (Jun et al., 2001; Richins, 1997; Bosque \& Martín, 2008), destinada a conhecer a forma como os turistas classificam as suas próprias emoções decorrentes das suas experiências gastronómicas no Algarve. Conforme apresentado no Quadro 4, cerca de 79\% dos respondentes classificaram as suas emoções sobretudo de modo positivo: $48,1 \%$ dos inquiridos diz-se emocionalmente satisfeito com as experiências gastronómicas que viveu; $61,6 \%$ indica ter ficado encantado ou ligeiramente encantado com essas experiências; $65,9 \%$ referiu estar ligeiramente impressionado ou impressionado com este tipo de experiências; e 53,1\% considerou-se surpreendido ou ligeiramente surpreendido com as mesmas. De realçar ainda que não se verificou a existência de turistas insatisfeitos, descontentes ou desapontados com este tipo de experiências. Uma pequena proporção de respondentes sentiu-se chateado com as experiências gastronómicas que viveu no Algarve $(0,3 \%)$.

Quadro 4 Emoções associadas à experiência gastronómica no Algarve

\begin{tabular}{|ccccc|}
\hline $\begin{array}{c}1 \\
\text { Satisfeito } \\
48,1 \%\end{array}$ & 2 & 3 & 4 & 5 \\
\hline $\begin{array}{c}\text { Encantado } \\
25,2 \%\end{array}$ & $30,5 \%$ & $13,2 \%$ & $8,1 \%$ & $\begin{array}{c}\text { Insatisfeito } \\
0 \%\end{array}$ \\
\hline 1 & 2 & 3 & 4 & 5 \\
$\begin{array}{c}\text { Impressionado } \\
30,7 \%\end{array}$ & $36,4 \%$ & $33,8 \%$ & $4,6 \%$ & $\begin{array}{c}\text { Descontente } \\
0 \%\end{array}$ \\
\hline 1 & 2 & 3 & 4 & 5 \\
$\begin{array}{c}\text { Surpreendido } \\
21,3 \%\end{array}$ & $35,2 \%$ & $26,3 \%$ & $7,8 \%$ & $\begin{array}{c}\text { Desapontado } \\
0 \%\end{array}$ \\
\hline
\end{tabular}

Fonte: Elaboração própria a partir dos outputs do SPSS

\section{FIDELIDADE À EXPERIÊNCIA GASTRONÓMICA E AO DESTINO} TURÍSTICO

O reconhecimento de que a gastronomia local poderá ter impacto na tomada de decisão do turista quer no momento da escolha do destino de férias quer em termos de intenções de recomendar a visita a amigos e familiares ou mesmo de regressar no futuro (Valle et al., 2011; Mark et al., 2012; Guerreiro et al., 2016), justificou a inclusão de questões destinadas a medir a fidelidade quer às experiências gastronómicas quer à própria região. Cerca de 73,4\% dos turistas 
respondentes dizem ter intenção de recomendar a gastronomia local a amigos e familiares. Paralelamente constata-se que $81 \%$ dos turistas demonstraram intenção de voltar a consumir gastronomia algarvia no futuro. Apenas 3\% afirmou não pretender voltar a viver esta experiência no futuro. Cerca de $69 \%$ dos turistas admitiram que as experiências gastronómicas que viveram no Algarve tem influência na intenção de recomendar o destino turístico. Apenas 16\% referiram que a experiência gastronómica não terá influência na sua intenção de recomendar o destino Algarve a amigos e familiares. A maioria dos turistas admite que as suas experiências gastronómicas contribuem positivamente para a sua intenção de regressar ao Algarve no futuro (esta é a situação expressa por $73 \%$ dos turistas da amostra). Estas informações encontram-se resumidas no Quadro 5.

Quadro 5 Fidelidade à experiência gastronómica no Algarve

\begin{tabular}{|c|c|c|c|}
\hline $\begin{array}{c}\text { Intenção de recomendar a } \\
\text { gastronomia algarvia aos } \\
\text { amigos e familiares }\end{array}$ & $\begin{array}{l}\operatorname{Sim} \\
73,4 \%\end{array}$ & $4,9 \%$ & $\begin{array}{l}\text { Talvez } \\
21,6 \%\end{array}$ \\
\hline \multirow{2}{*}{$\begin{array}{l}\text { Intenção de voltar a consumir } \\
\text { comida algarvia }\end{array}$} & $\operatorname{Sim}$ & Não & Talvez \\
\hline & $81,0 \%$ & $3,4 \%$ & $15,6 \%$ \\
\hline \multirow{2}{*}{$\begin{array}{l}\text { Influência da experiência } \\
\text { gastronómica vivida no Algarve } \\
\text { na intenção de recomendar } \\
\text { este destino turístico }\end{array}$} & Sim & Não & Talvez \\
\hline & $69,3 \%$ & $15,9 \%$ & $14,8 \%$ \\
\hline $\begin{array}{l}\text { Intenção de voltar ao destino } \\
\text { turístico do Algarve devido à }\end{array}$ & Sim & Não & Talvez \\
\hline experiência gastronómica & $46,9 \%$ & $21,1 \%$ & $32,0 \%$ \\
\hline
\end{tabular}

Fonte: Elaboração própria a partir dos outputs do SPSS

\section{CONSIDERAÇÕES FINAIS}

A gastronomia assume um papel de destaque não só como fator de sobrevivência, mas, cada vez mais como fator de prazer, pelo que se considera a degustação de alimentos um ato de lazer e convívio pela experiência vivenciada em interação e/ou como representação de status social. Pode ainda ser entendida como uma atitude de enriquecimento cultural, proporcionada pela descoberta de novos sabores. Neste contexto, a gastronomia surge como uma oportunidade para enriquecer a experiência turística e gerar recordações únicas e memoráveis através da associação de alimentos, cheiros ou sabores a lugares. 
Muito embora o Algarve seja considerado principalmente um destino turístico de sol e praia, a crescente competitividade entre destinos turísticos tem levado ao reconhecimento da necessidade de identificar e desenvolver os seus elementos diferenciadores. A gastronomia é um desses elementos chave. Neste enquadramento, o presente trabalho visou contribuir para um melhor conhecimento sobre a experiência gastronómica que os turistas vivem no Algarve.

A primeira conclusão é que os turistas que visitam a região do Algarve atribuem elevada importância à oportunidade para realizar refeições fora do hotel (92\%), experimentando deste modo a gastronomia típica do país para onde viajam (85\%), pois é considerada uma expressão da identidade e da cultura do destino turístico que toca diversos elementos da experiência turística. Em relação a experimentar a gastronomia da região durante a sua estada no Algarve, verifica-se que $81 \%$ dos turistas o fazem. Estes resultados sugerem que se deve incentivar a divulgação e a promoção da gastronomia típica da região ao nível dos estabelecimentos hoteleiros e de restauração. A gastronomia é reconhecidamente um fator diferenciador de um destino o qual vai ao encontro da necessidade do turista desfrutar de experiências marcantes, acrescentando valor à sua experiência turística (Henriques e Custódio, 2010; Richards, 2015).

Os turistas que experimentaram a gastronomia do Algarve destacam a importância dos produtos regionais e o despertar da curiosidade em relação à confeção e aos ingredientes que constituem os pratos, bem como ao que se come no país. Neste sentido, a utilização de produtos locais característicos pode ajudar a economia local, atribuindo maior diferenciação à sua gastronomia. A gastronomia é expressiva da cultura regional, sendo que a cozinha típica regional se transformou num produto turístico que deve ser promovido pelas entidades, empresas e indivíduos ligados ao turismo da região. Além disso, a divulgação dos ingredientes que constituem os pratos pode permitir aumentar a confiança do turista mais avesso ao risco de experimentar novos pratos. Por seu turno, a curiosidade em descobrir melhor a gastronomia do país pode gerar uma imagem positiva do mesmo e assim contribuir para a fidelidade dos turistas ao destino turístico (Valle et al., 2011). 
Quanto aos turistas que não experimentaram a gastronomia da região, $19 \%$ da amostra, o principal motivo prende-se com o desconhecimento das designações dos métodos de confeção dos ingredientes utilizados nos pratos tradicionais (52\%). Neste sentido, recomendam-se a identificação e a descrição dos ingredientes que integram os pratos típicos, bem como a ilustração de menus como forma de colmatar este desconhecimento. Além disso, a gastronomia Algarvia deverá ser mais divulgada nos guias gastronómicos e estes devem ser de mais fácil acesso aos turistas que visitam a região. Paralelamente deve incrementar-se a formação/qualificação dos profissionais do setor e dos próprios taxistas em relação à importância de divulgar a gastronomia da região e sobre o respetivo impacto na economia local.

Em relação à satisfação com a experiência gastronómica vivenciada no destino Algarve, verifica-se uma influência positiva, visto que $54 \%$ dos turistas se encontra bastante satisfeito com a experiência gastronómica na região, classificando positivamente a relação preço/qualidade. De realçar que a degustação de produtos ligados à gastronomia e à prova de vinhos tende a produzir emoções nos turistas que contribuem claramente para a formação da satisfação com a experiência turística e podem ser decisivas na competitividade do destino turístico, influenciando a vontade de repetir a escolha e de recomendar a região a potenciais turistas (Cai, Wu \& Bai, 2003; Valle et al., 2011).

Quanto à intenção de voltar a consumir ou recomendar a gastronomia experimentada no destino Algarve, constata-se que esta é bastante elevada, tendo em conta que $73 \%$ dos turistas pretende recomendar a gastronomia da região a amigos e familiares, bem como $81 \%$ afirma ter intenção de voltar a consumir a comida algarvia. Relativamente ao contributo da experiência gastronómica para a fidelidade ao destino, verifica-se que $69 \%$ dos turistas consideram que a experiência gastronómica influencia a recomendação do destino e $47 \%$ refere que a mesma tem influência na decisão de regressar ao destino no futuro. Conclui-se assim que os atributos do destino, como a gastronomia típica, têm influência na intenção de revisitar, sendo que a comunicação boca a boca.

Em termos de implicações, os resultados alcançados constituem uma importante fonte de informações úteis com base nas quais os responsáveis 
pela gestão do destinos turísticos, os gestores de empresas turísticas e outras entidades públicas regionais e locais, poderão fundamentar a sua tomada de decisões de marketing. Desde logo, a pertinência de se assumir que a gastronomia poderá ser uma fonte de produtos turísticos relevantes para os turistas podendo mesmo constituir uma interessante forma de diferenciar o destino dos seus principais concorrentes. Esta perspetiva é reforçada pela inclusão da Dieta Mediterrânica na lista do Património Mundial da Humanidade por parte da UNESCO. É pois de incentivar a divulgação da gastronomia típica da região, não apenas localmente e visando aos turistas que já se encontram no Algarve, mas também na divulgação externa que a entidade responsável pela gestão do destino operacionaliza junto dos principais mercados alvo, ainda nos seus países de origem. A gastronomia típica deverá ser assumida como uma importante fonte de vantagem competitiva da região. $O$ interesse demonstrado pelos turistas por realizar refeições fora do hotel coloca aos empresários locais do setor um conjunto de oportunidades de negócio que assim contribuirão para potenciar os efeitos multiplicadores do turismo.

Por último, sugere-se que a comunicação do destino turístico inclua testemunhos de turistas relativos às suas experiências gastronómicas na região, com base no reconhecimento da sua influência na decisão de regressar ao mesmo. De realçar que uma intervenção mais eficaz a nível de marketing e comunicação exige uma análise das características pessoais dos turistas, devido ao seu comportamento heterogéneo em função das mesmas. Em nível de material promocional (publicidade na televisão, internet, brochuras) sobre a gastronomia do Algarve, recomenda-se que o mesmo seja reforçado quer nos principais países de origem dos turistas, quer em países considerados estratégicos para a região e o país.

A presente investigação apresenta algumas limitações decorrentes das decisões tomadas ao longo do decurso do estudo, em função dos constrangimentos de tempo verificados no decorrer do processo. Neste sentido, a aplicação do questionário foi realizada no decorrer dos meses de outubro e novembro de 2014, época considerada baixa do turismo na região, o que impede a generalização, visto este ser um destino turístico bastante sazonal. Assim, recomenda-se a reaplicação do estudo nos meses de maior fluxo turístico na 
região, de forma a identificar possíveis especificidades relacionadas com cada segmento de turistas.

Reconhece-se também como limitação a administração do questionário ter ocorrido apenas junto de turistas estrangeiros que visitavam a região. No sentido de complementar estes resultados, recomenda-se a análise da relação entre as experiências gastronómicas, as emoções que a mesma suscita, a imagem do Algarve como destino turístico, a satisfação e fidelidade ao destino turístico por parte de turistas nacionais.

\section{REFERÊNCIAS}

AGARWAL, S. \& BRUNT, P. (2006). Social exclusion and English seaside resorts. Tourism Management, 27 (4), 654-670.

BOSQUE, I. \& MARTíN, H. (2008). Tourism Satisfaction, A Cognitive-Affective model. Annals of Tourism Research, 35 (2), 551-557.

CAI, L., WU, B. \& BAI, B. (2003). Destination image and loyalty, Cognizant Communication Corporation, 7, 153-162.

CHANG, R. C. Y., KIVELA, J., \& MAK, A. H. N. (2011). Attributes that Influence the Evaluation of Travel Dining Experience: When East meets West. Tourism Management, 32 (2), 307-316.

CHAPMAN, A. \& SPEAKE, J. (2011). Regeneration in a mass-tourism resort: The changing fortunes of Bugibba, Malta. Tourism Management, 32 (3), 482-491.

COSTA, C. (2009). O comportamento do turista estrangeiro no consumo da gastronomia portuguesa, Aveiro, Universidade de Aveiro.

CROMPTON, J. \& MCKAY, S. (1997). Motives of Visitors Attending Festival Events. Annals of Tourism Research, 24 (2), 425-439.

CRUZ, A. R. (2010). Tourism and Creativity in the Algarve: An Analysis of Regional Tourist Offer as an Attractor to the Creative Class. MSc thesis, University of the Algarve, Portugal.

CSAPÓ, J. (2012). The Role and Importance of Cultural Tourism in Modern Tourism Industry, Strategies for Tourism Industry - Micro and Macro Perspectives,.Dr. Murat Kasimoglu (Ed.). University of Pécs. Institute of Geografy Hungary.

DOLNICAR, S. (2002). A Review of Data-Driven Market Segmentation in Tourism. Journal of Travel and Tourism Marketing, 12 (1), 1-22. 
GALE, T. (2005). Modernism, Post-modernism and the Decline of British Seaside Resorts as Long Holiday Destinations: A Case Study of Rhyl, North Wales. Tourism Geographies 7 (1), 86-112.

GIMENES, M. (2012). Sentidos, sabores e cultura: a gastronomia como experiência sensorial e turística. In Netto, A. \& Gaetta, C. (eds.). Turismo de Experiência, São Paulo, Senac, p. 187201.

GUERREIRO, M., MENDES, J. \& HENRIQUES, C. (2014). Turismo Cultural em Análise. Contributos Metodológicos para a inventariação de Recursos Turísticos de Base Cultural (Cap. IV - Produtos). In Santos, M., Águas, P., Serra, F., Santos, J. A. (2014). TMS Conference Series - Perspetivas Contemporâneas em Turismo, UALG/ESGHT, p. 427-442.

GUERREIRO, M., PINTO, P., \& MENDES, J. (2016) Nature-based tourism in the Algarve: A fact or a myth? Journal of Spatial and Organizational Dynamics (fourhcoming).

HALL, C.; MITCHELL, R. (2000). We are what we eat: food, tourism and globalization, Tourism, Culture and Communication, 2, 29-37.

HALL, C. \& MITCHELL, R. (2005). Gastronomic tourism, in Novelli, M. (eds.) Niche tourism: contemporary issues, trends and cases, Oxford, Elsevier, p. 73-88.

HENRIQUES, C. \& CUSTÓDIO, M. (2010). Tourism and Gastronomy: The valuation of Algarve's Gastronomic Heritage, p. 73-77.

HENRIQUES, C., MENDES, J., GUERREIRO, M., AFONSO, C. \& MENDES, J. P. (2014). Turismo Cultural no Algarve, Universidade do Algarve, Portugal.

HEWISON, R. (1987). The Heritage Industry: Britain in a Climate of Decline. Disponível em http://portal.unesco.org/en/ev.php-URL_ID1/413055\& (acedido em março 2015).

HUGHES, H (1987). Culture as a Tourist Resource: A Theoretical Consideration. Tourism Management, 8 (3), 205-216.

JUN, S., HYUN, Y., GENTRY, J. \& SONG, C. (2001). The relative influence of affective experience on consumer satisfaction under positive versus negative discrepancies. Journal of Consumer Satisfaction, Disatisfaction and Complaining Behaviour, 14, 141-153.

KIVELA, J. \& CROTTS, J. C. (2006). Tourism and Gastronomy: Gastronomy's Influence on How Tourists Experience a Destination. Journal of Hospitality and Tourism Research, 30 (3), 354-377.

KIVELA, J.; CROTTS, J. C. (2009). Understanding Travelers' Experiences of Gastronomy Through Etymology and Narration. Journal of Hospitality and Tourism Research, 33 (2), 161-192 
KÖHLER, A. (2013). Preservação Patrimonial, Turismo Cultural e Transformação da Base Económica Local: Pioneirismo, Paradoxos e Retrocessos. Turismo: Visão e Acção, 244-262.

LASH, S. \& URRY, J. (1994). Economies of Sign and Space, London, Sage.

LEE, K., SCOTT, N. \& PACKER, J. (2014). Habitus and food lifestyle: In-destination activity participation of Slow Food members. Annals of Tourism Research, 48, 207-220.

MAK, A., LUMBERS, M. \& EVES, A. (2012). Globalisation and food consumption in tourism, Annals of Tourism Research, 30 (1), 171-196.

MENDES, J., HENRIQUES, C. \& GUERREIRO, M. (2015). Dos recursos às temáticas culturais na gestão do turismo cultural no Algarve. International Journal of Scientific Management and Tourism, 4 (october), 31-48.

OH, H., FIORE, A. M. \& JEOUNG, M. (2007). Measuring Experience Economy Concepts: Tourism Applications. Journal of Travel Research, 46 (November), 119-132.

OLIVER, R. (1999). Whence consumer loyalty? Journal of Marketing, 63 (4), 33-44.

OMC (2012). Policy Handbook on Work Plan for Culture 2011-2014 How to strategically use the EU support programmes, including Structural Funds, to foster the potential of culture for local, regional and national development and the spill-over effects on the wider economy?. Working Group on Cultural and Creative Industries Working Group of EU Member States Experts, European Union. Disponível em http://ec.europa.eu/culture/library/publications/ cci-policy-handbook_en.pdf (acedido em outubro de 2014).

PINE, J. \& GILMORE, J. (1999). Welcome to the Experience Economy. Harvard Business Review, 98407, 97-105.

PINE, J., Pepers, D. \& Rogers, M. (1995). Do you want to keep your customers forever? Harvard Business Review, March-April, 103-14.

POON, A (1998). Tourism, Technology and Competitive Strategies. Oxon: CABI Publishing.

RICHARDS, G (1996). Production and Consumption of European cultural Tourism. Annals of Tourism Research, 23 (2), p. 261-283.

RICHARDS, G. (2002). Gastronomy: an essencial ingredient in tourism production and consumption, in Hjalager, A.; Richards, G. (eds.) - Tourism and Gastronomy, New York, Routledge, p. 3-20.

RICHARDS, G. (2011). Creativity and Tourism The State of the Art. Annals of Tourism Research, 38 (4), 1225-1253. 
RICHARDS, G. (2015). Food experience as integrated destination marketing strategy. Paper present at the World Food Tourim Summit in Estoril, Portugal, p. 1-5.

RICHARDS, G., \& WILSON, J. (2006). Developing creativity in tourist experiences: a solution to the serial reproduction of culture? Tourism Management, 27 (86), 1408-141.

RICHINS, M. (1997). Measuring Emotions in the Consumption Experience. Journal of Consumer Research, 24 (2), 127-146.

SILVA, S. (2013). O património gastronómico regional enquanto fator de valorização da experiência turística: $O$ caso da indústria hoteleira de cinco estrelas no Algarve, Faro. Escola Superior de Gestão, Hotelaria e Turismo - Universidade do Algarve.

SMITH, M. K. (2009). Issues in Cultural Tourism Studies. London, Routledge.

STYLIANOU-LAMBERT, T. (2011). Gazing from home: Cultural tourism and art museums. Annals of Tourism Research, 38 (2), 403-421.

TUNG, V.W. S. \& J. R. RITCHIE (2011). Exploring the essence of memorable tourism experiences. Annals of Tourism Research, 38 (4), 1367-1386.

TURISMO DE PORTUGAL, I. P. (2006) 10 produtos estratégicos para o desenvolvimento do turismo em Portugal: Gastronomia e Vinhos, Lisboa. Disponível em: www.turismodeportugal. pt (acedido em: 27.09.2015).

TURISMO DE PORTUGAL, I. P. (2011) Plano Estratégico Nacional do Turismo, Propostas para Revisão no Horizonte 2015 - Versão 2.0, (2011), Lisboa. Disponível em www.turismodeportugal. pt (acedido em: 17.09.2014).

TURISMO DE PORTUGAL, I. P. (2013). Plano Estratégico Nacional do Turismo, Revisão e Objetivos 2013 - 2015, Lisboa. Disponível em: www.turismodeportugal.pt, (acedido em: 11.02.2015)

UNESCO (2002) Declaração Universal sobre a Diversidade cultural. Disponível em http:// unesdoc.unesco.org/images/0012/001271/127160por.pdf, consultado em março de 2015.

UNESCO. (2003). Convention for the Safeguarding of the Intangible Cultural Heritage. Paris: UNESCO.

UNESCO. (2009). The 2009 UNESCO Framework for Cultural Statistics (FCS). UNESCO Institute for Statistics.

UNESCO. (2010). The power of culture for development. Paris.

URRY, J. (1990). The Tourist Gaze: Leisure and Travel in Contemporary Societies. London: Sage.

VALLE, P., SILVA, J., MENDES, J. \& GUERREIRO, M. (2006). Tourist Satisfaction and Destination Loyalty intention: a structural and categorical analysis. International Journal of Business and Science and Applied management, I (1), 25-40. 
VALLE, P. O.; GUERREIRO, M.; MENDES, J. \& SILVA, J. A. (2011). The cultural offer as a tourist product in coastal destinations: The Case of Algarve, Portugal. Tourism and Hospitality Research, 11(4), 233-247.

VISITALGARVE (2014). Descubra a região. Disponível em www.visitalgarve.pt, acedido em: 07.06.2014.

ZUKIN, S. (2004). Dialogue on Urban Cultures: Globalization and Culture in an Urbanizing World, World Urban Forum, Barcelona. 